\title{
Design of Smart Grid Prosumer Communities via Online Social Networking Communities
}

\author{
A. J. Dinusha Rathnayaka, Vidyasagar M. Potdar, Samitha J. Kuruppu \\ Digital Ecosystems and Business Intelligence Institute \\ Curtin University \\ Perth, Western Australia
}

\begin{abstract}
Smart Grid (SG) achieves bidirectional energy and information flow between the energy user and the utility grid, allowing energy users not only to consume energy, but also to generate the energy and share it with the utility grid or with other energy consumers. This type of energy user who both consumes and generates energy is called the "prosumer". The sustainability of the SG energy sharing process heavily depends on its participating prosumers, making prosumer participation and management schemes crucial in the energy sharing approaches. However, the existing literature on SG energy sharing has given very little attention to managing prosumers. The contribution of this paper is twofold: first, we provide a comprehensive stateof-the-art review of managing prosumers in the context of SG and introduce the concept of goal oriented prosumer-communities through learning the aspects from social network communities. Second, we present a conceptual framework for forming a prosumer-community, based on online community formation. The significance of the prosumer community concept is that this will allow prosumers to collectively bargain for the energy with utility companies, thus offering the small players (prosumers) the negotiation power to be on par with big players (providers) and eliminate the dividing gap between them.
\end{abstract}

\section{Introduction}

The demand for energy in the world is continually rising. Worldwide energy consumption is expected to increase by 49 percent from 2007 to 2035[1]. The majority of the current demand is met by nonrenewable energy sources like coal, petroleum, natural gas etc., but the consumption of such nonrenewable energy sources contributes to greenhouse gas emissions and global warming. In today's world, the focus is more on shifting the energy usage by consumers from non-renewable sources to renewable sources of energy such as solar, water, and wind. Further, users are being encouraged not only to reduce their household energy consumption, but also to generate renewable energy and to either store the excess energy for future use or return the excess energy to the utility grid [3].

In order to devise such a framework, the vision of Smart Grid (SG) has been envisioned and proposed in the literature. SG is defined as "an electricity network that can intelligently integrate the behaviour and actions of all users connected to it - generators, consumers and those that do both- in order to deliver sustainable, economic and secure electricity supplies" [2]. The evolution of SG has become one of the greatest advancements of the modern era, as society faces dwindling and increasingly scarce nonrenewable energy resources followed by electricity shortage and unpleasant climatic changes due to greenhouse gas emissions [3]. SG integrates ICT (Information Communication Technologies) with advanced power electronic technologies to achieve a bi-directional flow of electricity and information [3]. Moreover, it has numerous desirable characteristics including: a self-healing capability which allows the SG to speedily detect and recover rapidly from disruptions; resistance to cyber attacks, which mitigates and is resilient against cyber security attacks; improved power quality; facilitation of a variety of generation options with greatly simplified interconnection process analogous to plug-and-play; flexibility and user-friendliness, to name a few.

SG is different from the traditional utility grid. It is important to note that the energy users are not active participants in this traditional model. The energy users just consume the energy supplied by a utility company and pay the energy bill; whereas, in the SG framework, users not only consume the energy; they also produce and supply the energy back to the grid. This type of energy user is known as a "prosumer".

In order for the SG framework to work seamlessly, it requires the development and integration of four main elements namely: (i) smart devices such as smart meters, smart gateways, etc., (ii) a framework for enabling bidirectional communication among smart devices, (iii) advanced software infrastructures, and (iv) a framework that enables the prosumers to participate in energy sharing. In the literature, a considerable amount of research has been done to address (i), (ii) and (iii) [3]. However, there has been very little investigation into the development of prosumer participation and 
management schemes. Moreover, existing schemes do not address several important issues such as offering higher bargaining power to the prosumers, achieving long-term sustainability and stability, etc. In fact, prosumer participation and management is critical in the energy-sharing process. For example, suppose a large group of dynamic prosumers suddenly refuses to share the energy with the main grid. In a worst case scenario, the main grid may not be able to satisfy the entire consumer demand by itself without the aid of that specific group of prosumers. This makes it necessary to develop an appropriate framework to manage the prosumers in order to successfully meet the increasing worldwide demand for energy.

In order to address this issue in the literature, in this research paper, we discuss a novel approach to managing the prosumers in the $\mathrm{SG}$, which integrates the SG prosumers into goal-oriented prosumer communities. According to the existing body of literature, some SG projects use the word "community" to indicate the entire prosumer base living in specific region [6]; but the concept we put forward in this paper is different. The fundamental significance of this concept of a prosumer community is that the communities of prosumers can collectively increase the amount of power to be auctioned or bought offering higher bargaining power in the energy market, thereby reducing the dividing gap between the utility providers and the prosumers [4-5]. However, the development of a sustainable prosumers community is not a simple task.

The novelty of this research paper can be discussed from two perspectives. First, we provide a detailed state-of-the-art review of prosumer participation and management schemes used by existing SG energy sharing approaches. In addition, we investigate the possibilities of applying the characteristics of most popular online social network communities to the establishment of prosumer communities. Second, we present a framework for the initial building block of a prosumer community: prosumer community formation. This framework emphasizes defining different types of prosumer community membership levels, and assigning prosumers to these different membership levels.

The rest of the article is organized as follows; Section 2 examines the overall position of managing prosumers in the contemporary SG research field, thereby identifying the open research issues in existing literature. In Section 3, we investigate the development of prosumer communities by examining the characteristics of online social network communities. Section 4 presents the proposed framework for community formation. Finally, future directions and concluding remarks are presented in Section 5 .

\section{Literature Review}

In this section, we discuss the prosumer participation and management schemes that have been utilized by existing SG energy sharing approaches.

According to the existing literature, most of the energy-sharing approaches integrate and manage the prosumers as a single entity (Fig. 1). This facilitates direct energy sharing between the prosumers and the utility grid and the energy-sharing decisions are made based on individual perceptions. In the literature, there are several research works on SG energy sharing schemes that involve individual prosumer participation. For instance, ADDRESS (Active Distribution networks with full integration of Demand and distributed energy RESourceS) [7] is a European initiative that builds a framework to encourage involvement in energy sharing of individual domestic and small commercial users, and builds new relationships between prosumers and utility companies. This highlights potential benefits and possible barriers related to active networks with distributed generation of renewable energy resources, while investigating real-time price signals and local optimization. Similarly, S-Ten Project [8] is another European project that enables an automatic re-configuration of a microgrid and facilitates the integration of demand resources into the control of the grid using market mechanisms. This investigates demand-side bidding techniques, which enables the prosumers to adjust their position in market bids and encourages participation of the prosumers who can even supply a small amount of energy to the grid. DR (Demand Response) [9] is a Canadian initiative, intended to minimize the energy demand during peak hours using real-time price demand response, while returning financial incentives to participants in return for their commitment to reduce energy consumption. On the other hand, iDEaS project (Intelligent Decentralized Energy-Aware Systems) [10] presents a novel market mechanism and strategies whereby trading agents can manage electricity trading within the SG. This trade management considers the impact of self-interested participating actors (prosumers) and the constraints of the transmission line capacity. The continuous double auction (CDA) method is the basis of this scheme and the autonomous congestion management is done by pricing the electricity flow.

The concept of Virtual Power Plants (VPPs) has been suggested in recent years as a means of integrating the many distributed energy resources (DERs) to SG. Literature recognizes VPP as "a technology for market visibility of many small distributed energy resources" [11]. The VPPs are managed so as to interact, negotiate or collaborate with other participants in the utility grid to enable joint coordination of energy consumption by a group of houses and thus attain overall enhanced energy 
efficiency. In the literature, two VPP management architectures, namely centralized architecture and decentralized architecture, are identified. In centralized architecture, grid-connected distributed power sources are controlled by a centralized controller [12]. The centralized controller is responsible for capturing power flow information, analysing, decision making and controlling prosumers in VPP. Pudjianto et al. [12] identify two roles of VPP in their centrally-controlled VPP framework namely Commercial VPP (CVPP) that handles market participation, and Technical VPP (TVPP) that handles system management activities. CVPP aggregates DER (Distributed Energy Resource) inputs like metering data, load forecasting data, and marginal cost characteristics to obtain a single VPP profile that represents the accumulated capacity of all DERs. By adding the inputs such as price forecasts in the market, CVPP results optimized DER schedules. On the other hand, TVPP aggregates the parameters obtained via CVPP such as operating schedules, bids and offers together with network information such as loading conditions and network constraints to obtain real-time network supervision and system balancing. eTelligence [13] is another such project that implements marketoriented operations to diminish the load on the utility grid in the city of Cuxhaven and surrounding areas. This architecture allows private prosumers' smart gateways as well as VPPs to place any quantities of energy on the market using an automated infrastructure linked to the market structure.

In contrast, in decentralized architecture, the agents can act independently without the involvement of a central controller. Decentralized VPP enables the prosumer to autonomously perform certain communications and decision-making tasks. For example, Dimeas and Hatziargyriou [14] have proposed the use of Multi Agent System Technology to enhance the operation of the VPP system, in which the agent-integrated VPPs communicate with the power market and also negotiate with other agents that control micro-sources [14]. Chalkiadakis et al. [15] use the cooperative game theory approach to form VPP, known as "Cooperative VPP". This framework enables even the smallest prosumer to autonomously perform certain communications and decision-making tasks. [15] has developed an energy pricing mechanism to ensure that the competitive rates are allowed in the procurement of cooperativeVPP energy, and also a payment scheme to distribute payments within the cooperative to guarantee that no sub-group has a sufficient incentive to establish a new, cooperative VPP.

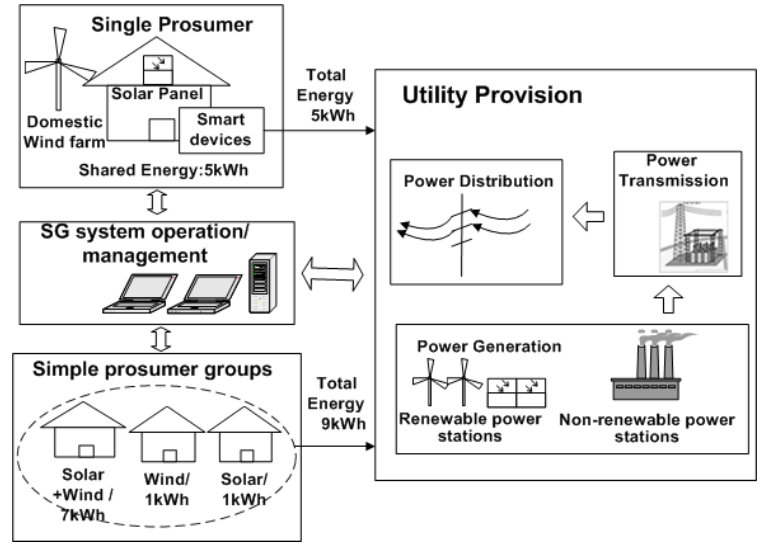

Figure1. Existing prosumer participation schemes

Although the literature presents several proposals for prosumer participation and management schemes, many extant issues still require further attention. In this section, we discuss the shortcomings of existing schemes, thereby identifying open research issues.

\subsection{Shortcomings of Existing Literature}

Table 1 summarizes the shortcomings in the existing literature, by checking whether the existing works effectively address the following questions.

Q1. Does the framework support energysharing between prosumers and the utility grid?

Q2. Does the framework support energysharing between consumers and prosumers?

Q3. What type of integration is used to connect prosumers to the SG: Individual (I), or simple-Group (G) ?

Q4. Does the framework present an appropriate method of forming prosumer aggregations rather than collecting prosumers in ad-hoc manner?

Q5. Is there an approach enabling the identification of negative behaviors of prosumers (e.g. prosumer suddenly decides to supply less energy than agreed)?

Q6. Is there an effective method of identifying and attracting more dynamic prosumers (prosumers capable of offering more energy to the grid) to increase the prosumer base?

Q7. Is there a comprehensive reward scheme that offers both financial and nonfinancial incentives to prosumers? 
Table 1. Shortcomings of existing literature $\mathrm{Y}=\mathrm{Yes}, \mathrm{N}=\mathrm{No}$

\subsection{Open Research Issues}

\begin{tabular}{|c|c|c|c|c|c|c|c|}
\hline $\begin{array}{l}\text { Approach } \\
\text { (Reference) }\end{array}$ & $\begin{array}{l}\mathbf{Q} \\
\mathbf{1}\end{array}$ & $\begin{array}{l}\mathrm{Q} \\
\mathbf{2}\end{array}$ & $\begin{array}{l}Q \\
3\end{array}$ & $\begin{array}{l}Q \\
4\end{array}$ & $\begin{array}{l}Q \\
5\end{array}$ & $\begin{array}{l}Q \\
6\end{array}$ & $\begin{array}{l}\text { Q } \\
7\end{array}$ \\
\hline ADDRESS project & Y & $\mathrm{N}$ & I & - & $\mathrm{N}$ & $\mathrm{N}$ & $N$ \\
\hline S-TEN Project & $\mathrm{Y}$ & $\mathrm{N}$ & 1 & - & $\mathrm{N}$ & $\mathrm{N}$ & $\mathrm{N}$ \\
\hline iDEaS Project & $\bar{Y}$ & $\mathrm{~N}$ & I & - & $\mathrm{N}$ & $\mathrm{N}$ & $\mathrm{N}$ \\
\hline DR Project & $\mathrm{Y}$ & $\mathrm{N}$ & I & - & $\mathrm{N}$ & $\mathrm{N}$ & $\mathrm{Y}$ \\
\hline $\begin{array}{l}\text { [12] (Pudjianto et } \\
\text { al. 2007) }\end{array}$ & $Y$ & $\mathrm{~N}$ & G & $\mathrm{N}$ & $\mathrm{N}$ & $\mathrm{N}$ & $\mathrm{N}$ \\
\hline $\begin{array}{l}\text { Smart House/ Grid } \\
\text { project }\end{array}$ & Y & $\mathrm{N}$ & G & $\mathrm{N}$ & $\mathrm{N}$ & $\mathrm{N}$ & $\mathrm{N}$ \\
\hline eTelligence project & Y & $\mathrm{N}$ & $\begin{array}{l}\mathrm{G} \\
/ 1\end{array}$ & $\mathrm{~N}$ & $\mathrm{~N}$ & $\mathrm{~N}$ & $\mathrm{~N}$ \\
\hline $\begin{array}{lll}\text { (Dimeas } & \text { et } & \text { al. } \\
2007)[14] & & \end{array}$ & Y & $\mathrm{N}$ & G & $\mathrm{N}$ & $\mathrm{N}$ & $\mathrm{N}$ & $\mathrm{N}$ \\
\hline $\begin{array}{l}\text { (Chalkiadakis et al. } \\
\text { 2011) [15] }\end{array}$ & Y & $\mathrm{N}$ & G & $\mathrm{N}$ & $\mathrm{N}$ & $\mathrm{N}$ & $Y$ \\
\hline
\end{tabular}

Although researchers in recent decades have strived to improve the role of the prosumer within the context of SG energy-sharing process, existing approaches have several shortcomings, thereby necessitating a new approach to prosumer participation and management. The fundamental shortcoming is that most of the existing approaches focus more on the concepts of building the relationship between the prosumers and the utility grid or modelling prosumers' behaviours in transferring energy, but fail to investigate the concepts of managing prosumers and establishing a sustainable prosumer base. In this section, we further analyse the research issues identified in the existing literature.

- Individual prosumers' failure to supply higher amount of energy: One of the major disadvantages of individual prosumer participation is that, in most cases, as a single entity, the prosumer is not going to produce enough energy to have any real bargaining power, and will therefore have to settle for a low price per kilowatt. In addition, certain individual prosumers may even fail to achieve at least the minimum amount of energy requested by the utility provision, and will therefore be left out of the entire energy sharing market.

- Lack of approaches that discuss the energy sharing between the prosumer and consumer: If consumers purchase energy from geographically closer prosumers without interrupting the main power grid, this will reduce the energy transfer cost, thereby reducing the energy loss and ultimately resulting in efficient energy exchange. In the current research field, no research has investigated the energy sharing between prosumers and consumers.
However, this is challenging, as in most cases, the individual prosumers are not capable of supplying a large quantity of energy, thereby failing to meet even one single consumer's energy requirements. Therefore, in most scenarios, it is necessary to have prosumer aggregations to supply an adequate amount of energy to the consumers. However, if these aggregations are not sufficiently stable and sustainable, it is doubtful whether, in the long term, they will be capable of meeting consumers' demands.

- There are no proactive methods for grouping, rather than merely aggregating prosumers,: It is true that prosumer aggregations can increase the prosumers' advantage in energy sharing. Prosumer aggregations in the form of VPPs can be established to enable the prosumers to collectively attain the critical mass essential to actively participate in the energy market. In fact, when compared to the individual prosumer participation method, prosumer aggregations are more effective in meeting the minimum energy thresholds requested by the utility provider. However, the existing models are not very effective in managing the prosumers within the VPP. One basic deficiency is that these existing prosumer aggregations (VPPs) are merely collected sets of prosumers. As a result, within the same virtual collection, there may be prosumers with completely diverse behaviours (e.g. different energy sources, different amounts of energy supplied to the grid, diverse preferences and interests, etc.). Such completely mismatched behaviours within the same set of prosumers can lead to misunderstandings and disputes among the prosumers within the virtual power station, ultimately results in prosumers leaving their virtual station and act solely in the energy-sharing process. Therefore, these simple prosumer aggregations are incapable of sustaining the energy market over a long period of time.

- Lack of goal-oriented nature of prosumers/ prosumer aggregations: The individual prosumer or prosumers within the virtual aggregation are not encouraged to achieve mutual goals in existing works. This can result in an ad-hoc pattern of energy supply to the grid; therefore, there may not be a guaranteed sufficient energy supply all the time, increasing the level of uncertainty within the entire energy-sharing process.

- Limited approaches to identify risks associated with negative behaviours of prosumers: In an effective prosumer management system, it is necessary to identify prosumer's negative behaviours, to analyze the associated vulnerability, and to resolve these negative events to avoid longterm negative effects. However, the existing methods lack these techniques [12]. In order to explain this 
issue more comprehensively, we categorize the prosumer behaviours as follows: (i) positive behaviours, (ii) neutral behaviours, and (iii) negative behaviours. Positive behaviour is when the prosumer acts in a manner more beneficial than what was initially expected, and offers more energy to the utility grid than agreed. Neutral behaviour is when a prosumer acts exactly according to expectations. Negative behaviour is when the prosumer does not act as agreed, and may be purposely producing less energy than agreed over a long period of time. In addition to these prosumers' activities, prosumers' opinions, future plans and interests can also be positive, negative or neutral. For example, the prosumer's interest in storing energy for future use rather than sharing with the utility grid can be a negative behaviour win terms of energy-sharing; and unfair distribution of financial benefits among the prosumers can create a negative opinion about the energy-sharing process. These negative events can be a serious threat to the viability of the energy-sharing process, if not resolved efficiently.

- Limited approaches to identify and attract more dynamic prosumers to grow the prosumer base: Relying on a minimum number of prosumers is short-sighted in a SG energy-sharing scheme, due to the uncertainty of climate-dependant green energy sources and prosumer behaviours. For example, if there is rain for a fortnight that prevents prosumers from generating sufficient energy via their roof-top solar panels, the minimum number of prosumers may not be able to satisfy even the minimum energy requirements of the utility company. If more prosumers are attracted to the energy-sharing process, especially dynamic prosumers who supply higher amounts of energy in the long term, the utility company can collect the amount of energy required to meet customer demand. However, in the literature [12], no clear approaches have been proposed to attract more dynamic prosumers and thereby increase the prosumer base.

- Lack of comprehensive prosumer rewarding schemes that consider both financial and nonfinancial incentives: Prosumer rewarding schemes play a critical role in creating a motivated prosumer base. These rewards can be either financial incentives like feed-in-tariff given for the energy generated and supplied to the grid, or non-financial rewards such as social respect, reputation and popularity for generating and sharing green energy. In order to establish an effective, rewarding scheme, both these financial and non-financial incentives should be optimally amalgamated and offered fairly to the prosumers. However, the existing approaches have not proposed any comprehensive prosumer reward schemes; rather they consider only the financial returns to the prosumers.
It is obvious that existing works do not comprehensively address several important aspects of managing prosumers. . In order to address these issues, we introduce and discuss a new concept whereby prosumers are integrated to SG in the form of into goal-oriented prosumer communities (Fig. 1).

\section{Prosumer-Community \& Social Network Community}

In this section, we investigate the features of the prosumer community by examining the various aspects and characteristics of current, flourishing online social networking communities. Prior to this, we first briefly analyze the key aspects of online communities and accordingly examine the steps associated with the development of prosumer communities.

\subsection{Aspects of online community}

In the literature, the term "online community" is defined as "a social network of individuals who interact through online, potentially crossing geographical and political boundaries in order to pursue mutual interests or goals" [16]. The features of online communities have been extensively utilized in diverse areas such as healthcare, education, peerto-peer services, and more prominently in social network/blog space communities [17-20]. In this section, we examine social network communities. The social network community life cycle includes three main processes: formation, growth and overall management (Table.2, Table.3 and Table.4).

As illustrated in Table.2, the establishment of a social network community requires two main tasks: determination of social network community prequalification criteria and assignment of suitable users. It is a well-known fact that prerequisites for joining social network communities such as Facebook and Twitter are: possessing a unique user identifier and a valid email address. The unique identifier is used to differentiate the users and the email address is used to send the activation link. Social network communities allow any internet user to join the community by simply creating an account, mostly free of charge. One of the main challenges faced by current social network communities is the selection of appropriate members for the community, while avoiding the members who may post inappropriate content that can damage the reputation of the other members as well as the morale of the community. However, it is not easy to prevent inappropriate users from joining a social network community. But, community administrators usually allow other members to report the abusive contents, which ultimately results in the cancellation of inappropriate members' accounts. 
The growth of a social network community can be achieved in two ways: promoting (advertising) the community, and attracting dynamic members to expand the community (Table.3). Usually, the promotion of social network communities is done through viral marketing and invitations through friends; hence, it can reach more people with a limited budget. Social network communities such as Facebook are able to attract more members by presenting a highly customizable platform with more interactive features compared to those of other competitors. The members within the social network community can be either passive, who only view the posts, or active, who actually contribute posts and comments on other posts. In particular, online communities established around certain interests such as medicine or agriculture may require the comments and posts of experts in those fields, which determines the viability of that community. In order to attract such members, such social network communities usually advertise premium features at a lower rate or free of charge for such members, and also offer non-financial rewards such as reputation and popularity.

The third process we identify in the social network community is the overall community management (Table.4), which comprises four main tasks: reward distribution, behavior management, securityand loyalty management, and deactivation management. Since most social network communities do not provide financial incentives, in most cases there are no hard and fast rules governing the fair distribution of non-financial rewards and incentives such as popularity, opportunities or reputation. In some communities, the dynamic members may receive greater prestige and reputation than the others. When it comes to behavior management, posting negative comments about other members can adversely affect that member's reputation; however, it may or may not affect the overall goal of the communities. The social network communities usually cannot predict the behaviours of their members but have implemented policies to blacklist or block undesirable members and report any inappropriate content. When we talk about security and loyalty with regard to the social network community, social network communities face high security threats, as there is low access security thereby enabling any user to join the community and view or post the content. However, some social network communities have introduced a member referral process to identify new members, preventing any member to login to the system. Moreover, a social network community member can join a number of social network communities with the same interest, and this may result in more knowledge sharing. Most of the social network communities allow their members to unsubscribe or delete their membership with just one click. If the member is a passive member, the deactivation of this member might not have much impact on the overall performance of the community.

\subsection{Aspects of prosumer community}

Based on the above analysis of online social network communities, here we attempt to identify the different aspects of prosumer communities. Accordingly, we view the development of prosumer communities in terms of three main processes, namely: prosumer community formation, prosumer community growth and prosumer community overall management. In this section, we analyse these three processes.

3.2.1. Prosumer-community formation. The formation or establishment of a prosumer community (Table.2) is not as simple as that of a social network community. In contrast to the simple user subscription method of joining social network communities, the membership of a prosumer community is limited only to the prosumers having distributed energy resources and the community formation should consider whether there is an exact match between the prospective prosumer and the prosumer community's pre-qualification criteria. Hence, the subscription to a prosumer community can be a long and complicated process that involves interactions between different authorized agents. Therefore, it is more challenging to determine the community pre-qualification criteria and accept suitable prosumers into the community, when compared to the joining process of a social network community. The community pre-qualification criteria of a prosumer-community should be properly defined and take into consideration many influential parameters related to current prosumers, current rate of power in the competitive power market, pricing policies, etc [5]. The prosumer-community membership levels should each be characterized by respective pre-qualification criteria and the prosumers should be assigned membership of the most appropriate community. One way of establishing a prosumer community group is illustrated in Fig.2. Similar to the online community, the prosumer-community is also established by aggregating "prosumers" from different locations but having similar interests and energy behaviours (e.g. similar energy sources, similar amount of energy supplied to the grid, etc.). For example, prosumers who offer energy between $20-50 \mathrm{kWh}$ through their domestic solar panels will be added to one community group and the prosumers who offer energy between $51-100 \mathrm{kWh}$ using domestic solar and wind sources will be added to another community group. Before assigning the prosumers to a particular group, the initial step in the prosumer subscription process should be the capture of the 
households' energy behaviours that affect the energy sharing process. This can be done either explicitly by directly contacting potential prosumers or implicitly by observing the smart meters in the long term. Some of the many quantitative energy behaviours are ascertained by noting average daily power generation and consumption, capacity of smart storage, expected power variation due to the future plans, seasonal power variation (green power variation due to climate change), prosumer's preferred quantity of energy for future consumption, and prosumer's preferred quantity of energy for sharing etc. After analysing the diverse energy behaviours of prosumers, the prosumers with common interests can be segmented and assigned to the appropriate community membership levels. Moreover, those communities should be stimulated to achieve a predefined common goal (e.g. to achieve at least the minimum amount of energy requested by the utility provider, the minimum amount of energy required to obtain higher bargaining power in the energy market, etc.). Since the prosumer-community groups are encouraged to produce a predefined quantity of collective energy in the long term, this will lead to higher bargaining power for its members in the long term. Moreover, since the members of each community exhibit similar behaviours, it makes the incentive distribution and maintenance process easier, and reduces conflicts and discrepancies among members, and in turn creates sustainable communities.

3.2.2. Prosumer-community growth. Now we discuss the growth of the prosumer community in terms of tasks we discussed for social networks (Table.3); prosumer-community promotion (advertising), identifying and attracting dynamic prosumers. Unlike the social network community, a comprehensive bootstrapping process is necessary for the growth of the prosumer community, so that prosumers waiting to join the community can clearly discover community regulations and conditions. The promotion of prosumer communities in order to attract more members should be done by a responsible body (e.g. utility company), by clearly presenting rules and regulations, and the prequalification criteria. If a community is to expand, it is necessary to analyse the historic energy profiles of prosumers and identify more dynamic prosumers who can provide a greater amount of energy for long periods of time. To encourage more dynamic members to join the prosumer-communities, the differential incentive schemes that reflect the higher amounts of energy agreed by more dynamic prosumers can be introduced.

\subsubsection{Prosumer-community Overall}

Management. As the prosumer communities grow with the introduction of new members, the challenges of managing these communities will also increase. Similar to the analysis of social network community management, we discuss prosumer community management in terms of the following criteria: reward distribution, behavior management, security and loyalty management, and deactivation process (Table.4). Usually, the prosumers are given a feedin-tariff for the energy shared. Resolving challenges such as how to assess the contribution of individual prosumers and how to fairly distribute the incentives will be more complex in a prosumer community reward distribution scheme, compared to that of social network communities.

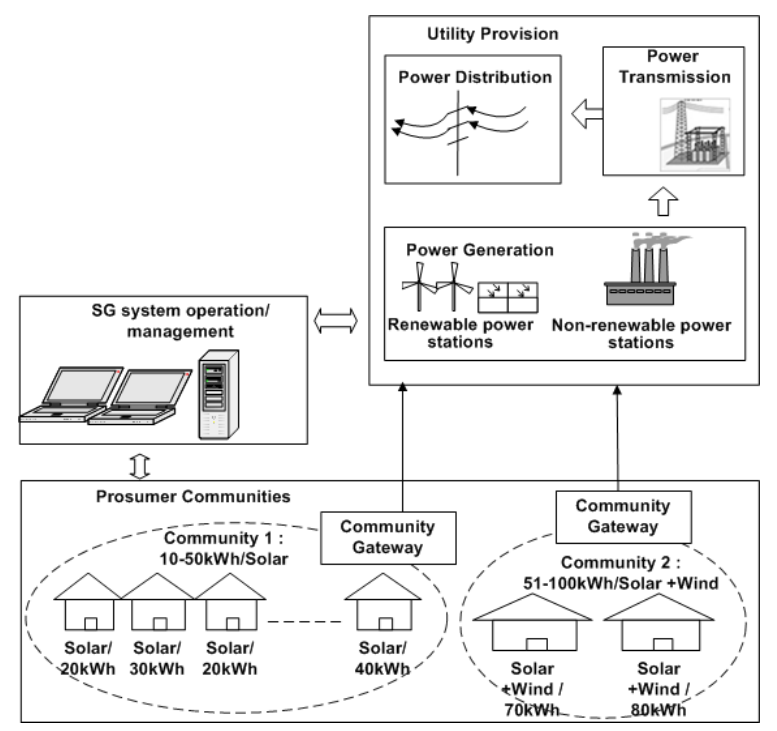

Figure 2. Prosumer Community Architecture

In order to resolve these challenges, prosumer contributions to the sustenance of the overall community performance should be properly realized using contribution assessment schemes, and ranking techniques and incentives should be accordingly distributed. On the other hand, behavior management is also a critical component of prosumer-community management. As discussed in Section 2.2, prosumer behaviors can also be negative. For example, when a prosumer supplies less energy than agreed, this reduces the incentives to all the members of the community, thereby inducing prosumers to leave the community. The prosumer community should manage these negative events very effectively, as unlike social network communities, losing a single prosumer can make huge impact on the overall community performance. Therefore, efficient and effective risk assessment schemes and negotiation schemes are necessary to clearly recognize the 
Table 2. Community formation concepts of social network community and prosumercommunity

\begin{tabular}{|c|c|c|c|c|c|c|}
\hline \multirow{3}{*}{ 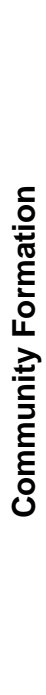 } & & $\begin{array}{l}\text { Social network } \\
\text { community }\end{array}$ & SG prosumer community & Challenges & $\begin{array}{l}\text { Solutions for } \\
\text { Social } \\
\text { network } \\
\text { communities }\end{array}$ & $\begin{array}{l}\text { Suggestions for } \\
\text { prosumer } \\
\text { communities }\end{array}$ \\
\hline & 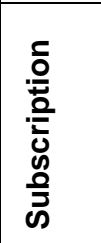 & $\begin{array}{l}\text {-Any internet } \\
\text { user can be a } \\
\text { member. } \\
\text {-Mostly free } \\
\text { online } \\
\text { subscription. }\end{array}$ & $\begin{array}{l}\text {-Restricted to the prosumers } \\
\text { (having DERs) } \\
\text {-Subscription can be a long } \\
\text { and complicated process }\end{array}$ & \multirow{2}{*}{$\begin{array}{l}\text { Ensuring } \\
\text { appropriatene } \\
\text { ss of } \\
\text { members } \\
\text { seeking } \\
\text { subscription } \\
\text { Determining } \\
\text { appropriate } \\
\text { pre- } \\
\text { qualification } \\
\text { criteria }\end{array}$} & \multirow{2}{*}{$\begin{array}{l}\text {-Difficult to } \\
\text { restrict } \\
\text { inappropriate } \\
\text { members, but } \\
\text { can } \\
\text { report/cancel } \\
\text { their } \\
\text { membership } \\
\text { and } \\
\text { inappropriate } \\
\text { content }\end{array}$} & \multirow{2}{*}{$\begin{array}{l}\text {-Profile } \\
\text { prosumers' } \\
\text { energy } \\
\text { behaviours to } \\
\text { select suitable } \\
\text { members } \\
\text {-Consider all } \\
\text { influential factors } \\
\text { in prosumers' } \\
\text { energy profiles to } \\
\text { determine pre- } \\
\text { qualification } \\
\text { criteria }\end{array}$} \\
\hline & 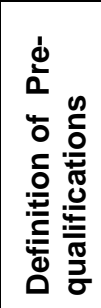 & $\begin{array}{l}\text {-Unique } \\
\text { identifier (to } \\
\text { differentiate } \\
\text { users) } \\
\text {-Valid email } \\
\text { address (to mail } \\
\text { the account } \\
\text { activation link) }\end{array}$ & $\begin{array}{l}\text {-Valid identity of a prosumer } \\
\text {-Historic and real-time } \\
\text { energy behaviour information } \\
\text { (consumption and } \\
\text { generation) } \\
\text {-Reliable method of receiving } \\
\text { financial benefits }\end{array}$ & & & \\
\hline
\end{tabular}

Table 3. Community growth concepts of social network community and prosumer-community

\begin{tabular}{|c|c|c|c|c|c|c|}
\hline \multirow{3}{*}{ 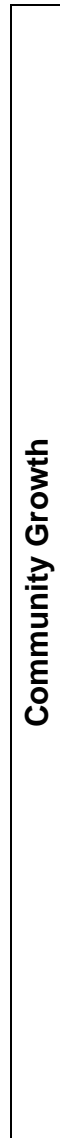 } & & $\begin{array}{l}\text { Social network } \\
\text { community }\end{array}$ & $\begin{array}{l}\text { SG prosumer } \\
\text { community }\end{array}$ & Challenges & $\begin{array}{l}\text { Solutions for } \\
\text { Social network } \\
\text { communities }\end{array}$ & $\begin{array}{l}\text { Suggestions for } \\
\text { prosumer } \\
\text { communities }\end{array}$ \\
\hline & 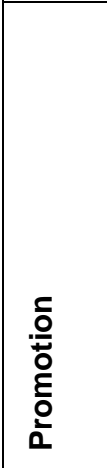 & $\begin{array}{l}\text {-Through viral } \\
\text { marketing } \\
\text {-Invitations } \\
\text { through friends, } \\
\text { hence reach } \\
\text { more people } \\
\text { with a very } \\
\text { limited } \\
\text { marketing } \\
\text { budget }\end{array}$ & $\begin{array}{l}\text {-Will be more } \\
\text { constructive if the } \\
\text { promotion is done } \\
\text { through a responsible } \\
\text { body (e.g. utility } \\
\text { company). } \\
\text {-Social network } \\
\text { communities can be } \\
\text { used to promote SG } \\
\text { prosumer community }\end{array}$ & $\begin{array}{l}\text { Effective } \\
\text { methods of } \\
\text { advertising } \\
\text { the } \\
\text { community }\end{array}$ & $\begin{array}{l}\text {-Present highly } \\
\text { customizable } \\
\text { platform, } \\
\text { attractive } \\
\text { appearance and } \\
\text { new interactive } \\
\text { features. } \\
\text {-Broadcast the } \\
\text { popularity of the } \\
\text { community } \\
\text { compared to } \\
\text { competitors. }\end{array}$ & $\begin{array}{l}\text {-Clear presentation } \\
\text { of rules and } \\
\text { regulation, } \\
\text { distribution of } \\
\text { incentives, etc. } \\
\text {-Introduce higher } \\
\text { rate for energy. } \\
\text {-Reduce the } \\
\text { minimum energy } \\
\text { threshold to join the } \\
\text { community. }\end{array}$ \\
\hline & 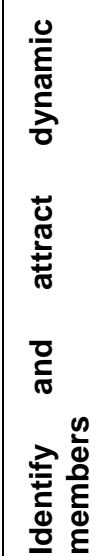 & $\begin{array}{l}\text {-Passive (only } \\
\text { viewing) or } \\
\text { active (actually } \\
\text { posting). } \\
\text { The contribution } \\
\text { is mostly } \\
\text { qualitative and } \\
\text { difficult to } \\
\text { measure. } \\
\text {-Mostly offering } \\
\text { non financial } \\
\text { incentives for } \\
\text { dynamic } \\
\text { members }\end{array}$ & $\begin{array}{l}\text {-Only Active members } \\
\text { are considered } \\
\text { (actually involve in } \\
\text { energy sharing), but } \\
\text { contribution is mostly } \\
\text { quantitative and easily } \\
\text { measurable. } \\
\text {-Must consider financial } \\
\text { incentives to attract } \\
\text { new members. } \\
\text {-Highlight the social } \\
\text { respect the members } \\
\text { will receive by joining } \\
\text { the energy sharing } \\
\text { process }\end{array}$ & $\begin{array}{l}\text {-Identifying } \\
\text { the more } \\
\text { dynamic } \\
\text { members } \\
\text {-Attracting } \\
\text { more } \\
\text { dynamic } \\
\text { members }\end{array}$ & $\begin{array}{l}\text {-Identify } \\
\text { possible active } \\
\text { and passive } \\
\text { members } \\
\text { through } \\
\text { analysing their } \\
\text { activities. } \\
\text {-Offer premium } \\
\text { features at lower } \\
\text { rate and higher } \\
\text { popularity } \\
\text { (reputation) for } \\
\text { active users. }\end{array}$ & $\begin{array}{l}\text {-Identify dynamic } \\
\text { prosumers via } \\
\text { historic energy } \\
\text { sharing profile } \\
\text { analysis } \\
\text {-Introduce } \\
\text { differential incentive } \\
\text { schemes to reflect } \\
\text { the prosumers' } \\
\text { agreed energy } \\
\text { contribution. }\end{array}$ \\
\hline
\end{tabular}


Table 4. Overall community management concepts of social network community and prosumer-community

\begin{tabular}{|c|c|c|c|c|c|c|}
\hline & & $\begin{array}{l}\text { Social network } \\
\text { community }\end{array}$ & SG prosumer community & Challenges & $\begin{array}{l}\text { Solutions } \\
\text { Social } \\
\text { network } \\
\text { communities }\end{array}$ & $\begin{array}{l}\text { Solutions for } \\
\text { prosumer } \\
\text { communities }\end{array}$ \\
\hline & 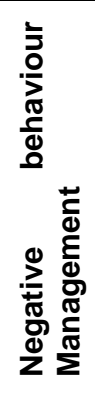 & $\begin{array}{l}\text { - Posting } \\
\text { comments that } \\
\text { adversely affect the } \\
\text { name of the } \\
\text { community. } \\
\text { - One member's } \\
\text { behaviour may not } \\
\text { have much effect on } \\
\text { overall goal. }\end{array}$ & $\begin{array}{l}\text { - Prosumer offers lower } \\
\text { amount of energy than } \\
\text { agreed for a long duration } \\
\text { of time. } \\
\text { - One member's negative } \\
\text { behaviours affect all the } \\
\text { members of the community } \\
\text { - Proper scheme required } \\
\text { to handle such scenarios } \\
\text { without losing the } \\
\text { prosumer's contribution. }\end{array}$ & $\begin{array}{l}\text { - Identifying } \\
\text { and assessing } \\
\text { the negative } \\
\text { behaviours }\end{array}$ & $\begin{array}{l}\text { - Blacklisting/ } \\
\text { blocking a } \\
\text { specific } \\
\text { person. }\end{array}$ & $\begin{array}{l}\text { - Negotiate } \\
\text { with prosumers } \\
\text { to obtain higher } \\
\text { amounts of } \\
\text { energy. } \\
\text { - Policy-based } \\
\text { approaches. }\end{array}$ \\
\hline 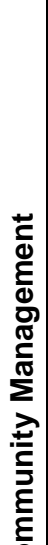 & 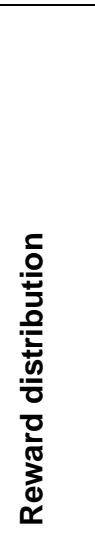 & $\begin{array}{l}\text { - Usually no } \\
\text { financial return for } \\
\text { the general } \\
\text { information shared } \\
\text { by users, unless } \\
\text { particularly } \\
\text { mentioned (e.g. } \\
\text { premium features) } \\
\text { - Non financial } \\
\text { rewards are } \\
\text { Reputation, } \\
\text { popularity, new } \\
\text { opportunities (for } \\
\text { the users and their } \\
\text { businesses) }\end{array}$ & $\begin{array}{l}\text {-Financial incentives are } \\
\text { given to the prosumers for } \\
\text { the energy shared. } \\
\text {-Non-financial reward is the } \\
\text { social respect acquired } \\
\text { through the sharing of } \\
\text { excess energy }\end{array}$ & $\begin{array}{l}\text { - Assessing } \\
\text { actual } \\
\text { contribution of } \\
\text { prosumers } \\
\text {-Fairly } \\
\text { distributing } \\
\text { incentives }\end{array}$ & $\begin{array}{l}\text { - Identify } \\
\text { active and } \\
\text { passive } \\
\text { behaviours. } \\
\text { - Offer } \\
\text { premium } \\
\text { features at } \\
\text { lower rate and } \\
\text { higher } \\
\text { popularity } \\
\text { (reputation) for } \\
\text { active users. }\end{array}$ & $\begin{array}{l}\text { - Assess the } \\
\text { contribution } \\
\text { (energy } \\
\text { offered) and } \\
\text { distribute } \\
\text { incentives } \\
\text { (financial and } \\
\text { non-financial) } \\
\text { based on the } \\
\text { energy } \\
\text { contribution. }\end{array}$ \\
\hline 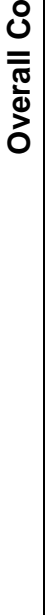 & 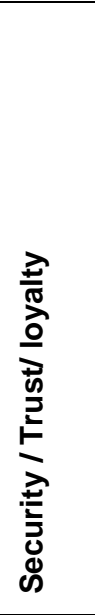 & $\begin{array}{l}\text { - High security } \\
\text { threats, spasm, } \\
\text { hackers } \\
\text { - Low access } \\
\text { security: simple } \\
\text { password } \\
\text { authentication } \\
\text { - One user may join } \\
\text { more than one } \\
\text { social network } \\
\text { community } \\
\text { simultaneously for } \\
\text { the same objective } \\
\text { (may result in more } \\
\text { knowledge sharing) }\end{array}$ & $\begin{array}{l}\text { - Less security threats, but } \\
\text { slight information leak can } \\
\text { cause huge loss. } \\
\text { - High access security: } \\
\text { Membership proof to } \\
\text { access resources can } \\
\text { involve with many signed } \\
\text { statements (credentials). } \\
\text { - Joining two communities } \\
\text { may cause disloyalty and } \\
\text { penalties and sometimes } \\
\text { may be disadvantageous to } \\
\text { the prosumer ( Offering } \\
\text { more energy level to one } \\
\text { community results in higher } \\
\text { rate of incentive than } \\
\text { offering to many) }\end{array}$ & $\begin{array}{l}\text { - With } \\
\text { growing } \\
\text { community, } \\
\text { establishing } \\
\text { higher security } \\
\text { - Assessing } \\
\text { loyalty and } \\
\text { trust of } \\
\text { prosumers }\end{array}$ & $\begin{array}{l}\text { - Photo proof } \\
\text { to access } \\
\text { resources. } \\
\text { - Member } \\
\text { referral to } \\
\text { identify new } \\
\text { members. }\end{array}$ & $\begin{array}{l}\text { - Implement } \\
\text { regulations for } \\
\text { breach of trust } \\
\text { within the } \\
\text { community } \\
\text {-Policy based } \\
\text { approaches to } \\
\text { discourage } \\
\text { disloyal } \\
\text { behaviours of } \\
\text { prosumers. }\end{array}$ \\
\hline & 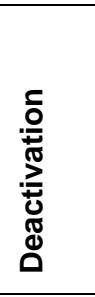 & $\begin{array}{l}\text { Simple deactivation } \\
\text { (e.g. one click of a } \\
\text { button } \\
\text { "unsubscribe") } \\
\text { Deactivation of one } \\
\text { user account might } \\
\text { not greatly affect the } \\
\text { overall sustenance }\end{array}$ & $\begin{array}{l}\text { Deactivation process can } \\
\text { be complicated } \\
\text { Deactivation of one } \\
\text { prosumers account can be } \\
\text { extremely negative to the } \\
\text { overall performance } \\
\text { (reduce community's } \\
\text { overall energy) }\end{array}$ & $\begin{array}{l}\text { Means of } \\
\text { encouraging } \\
\text { prosumers to } \\
\text { remain in a } \\
\text { community for } \\
\text { longer }\end{array}$ & $\begin{array}{l}\text {-Offer } \\
\text { premium } \\
\text { features } \\
\text { long-term } \\
\text { members }\end{array}$ & $\begin{array}{l}\text { Increased rate } \\
\text { of incentives } \\
\text { for long-term } \\
\text { prosumers }\end{array}$ \\
\hline
\end{tabular}


impact of negative events and discourage prosumers' negative behaviors. Additionally, achieving security, loyalty and trust in prosumer communities is far more crucial than it is in social network communities. For example, joining and supplying energy to multiple communities can be considered as disloyal behavior of prosumers, as it may reduce the collective energy of the entire community, which can adversely affect the incentives received by other prosumers in the same community. In addition, security threats that cause even slight information leak can produce huge losses in incentives for all the member-prosumers. Therefore in order to face these challenges, secured information transfer is necessary to avoid cyber attacks and the policies that prevent the breach of disloyalty and trust should be enforced within the community management. Finally the prosumer-community deactivation may not be as straightforward as it is in social network communities. The deactivation of one prosumer may cause incentive losses to all the members of the community and thus should be urgently replaced by a prosumer having approximately similar behaviours. Therefore, appropriate deactivation procedures should be enforced which take into consideration that member's historic energy contributions and membership duration. The penalties should consider the financial loss that could be incurred by other members due to the deactivation of that member.

According to this analysis, the complicated challenge of applying existing research findings of online community based approaches to build the prosumer communities is evident. After a major revision, we can apply some aspects of social network communities to the building of prosumer communities. In the next section, we propose a framework for the establishment of a prosumer community based on the tasks identified in this section; the definition of prosumer community prequalification criteria, and assignment of prosumers to different categories.

\section{Prosumer-Community Framework}

In our previous research paper [4], we discuss the abstract conceptual structure for prosumercommunity formation, prosumer-community growth, and prosumer-community overall management. In this section, we propose a new framework for the establishment of a prosumer community based on two main stages:

1) Stage 1: Defining the prosumer membership levels (pre-qualification criteria)

2) Stage 2: Prosumer profiling and assignment to the appropriate community groups
Figure.3 illustrates an abstract view of the framework. The main actor involved is the 'Community Coordinator' who is involved in both stages during the initial time period of the community's 'Life Frame'. The 'Community coordinator' is an entity or a group of entities who determine the membership levels followed by community pre-qualification criteria, are involved in prosumer profiling and assignment, and coordinate different individual prosumers to achieve a common goal. The 'Life frame' of the prosumer community starts from the time the community is defined and initiated, and ends when the community ceases to exist. The lifetime of a community can be broken into a discrete number of non-overlapping time periods and in this paper our focus is only on the initial time period of the life frame, which involves defining the prosumer community membership levels and the profiling and assigning of prosumers. In the next two sections, we explain these two stages in more detail.

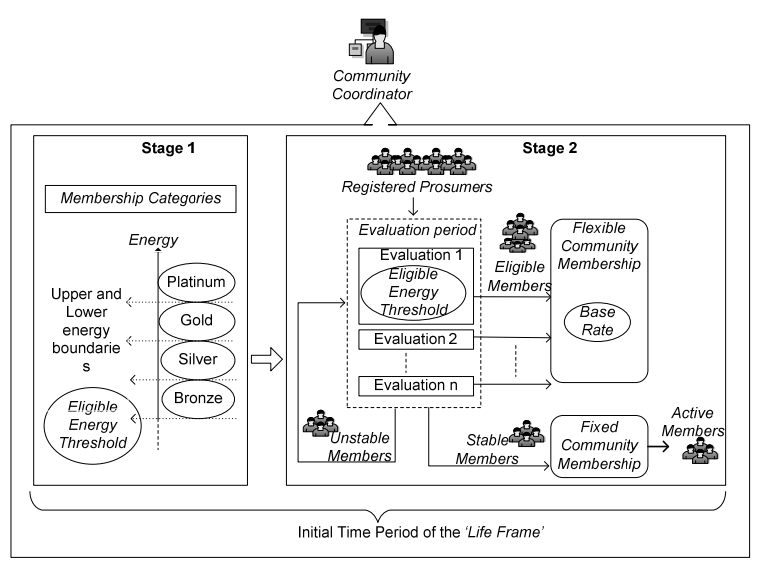

Figure 3. Community Formation Framework

\subsection{Stage 1}

In stage 1, the prosumer's membership level is determined. The main aim of stage 1 is to establish community membership levels or categories. In this framework, we refer to these as Bronze, Silver, Gold and Platinum. These categories are defined by the community coordinator. Each membership category has particular privileges. The higher the membership level, the greater the privileges and the more benefits a member can gain. Bronze category is the entry level, and Silver, Gold and Platinum levels offer respectively higher status. Each membership category is associated with upper and lower energy boundaries. The lower energy boundary of the entry level (bronze) membership category emphasizes the 'Eligible Energy Threshold'. The two key terms to be noted from the above are: 
- Membership categories: 'Membership Categories' are used to describe the community groups in the community-based energy sharing network. In this framework, there are four different categories: Bronze, Silver, Gold, and Platinum.

- Eligible Energy Threshold: 'Eligible Energy Threshold' is the lowest energy threshold required to join the community-based energy sharing network.

Now we briefly explain the methodology used to accomplish the tasks of stage 1 . In order to determine the different membership levels, firstly the historical energy profiles of the prosumers will be captured, which is the input to stage 1 . The possible source of historic energy data would be the energy databases of energy retailers. Then the data are clustered into four groups using a suitable clustering technique. These represent four community-group membership levels: bronze, silver, gold and platinum. After analyzing these clusters, the final outcome of this stage is the non-overlapping upper and lower energy boundaries associated with each cluster. 'Eligible Energy threshold' is automatically assigned as the lowest energy boundary of all the clusters.

\subsection{Stage 2}

The abstract view of stage 2 can be illustrated as follows: this stage involves the assigning of prosumers to suitable 'Fixed Membership' levels. The 'Community Coordinator' first acknowledges the 'Registered Prosumers' according to the conditions of the 'Evaluation Period', which covers the rules and governance with which prosumer must comply during this 'Evaluation Period', and a range of activities that need to be delivered by the prosumer to obtain the different membership statuses: 'Flexible Membership' status, and 'Fixed Membership' status. All the 'Registered Prosumers' should successfully complete the 'Evaluation Period' in order to achieve the 'Fixed Membership' levels. During the 'Evaluation Period', the prosumer initiates energy sharing for a specific number of transactions. The prosumer's energy contribution is evaluated and the 'Eligible Prosumers' are assigned to a 'Flexible community-membership' with 'Base rate' incentives after each energy transaction within the 'Evaluation Period'. After the 'Evaluation Period', the 'Community Coordinator' evaluates the overall performance of the prosumer during the entire period and assigns 'Stable prosumers' to a 'Fixed community membership' level, giving them 'Active Member' status. The 'Unstable prosumers' still remain in the 'Evaluation Period'. Following are the definitions of the key terms and actors involved in the $\mathrm{SG}$ process.
- Registered Prosumer is any prosumer who shows interest in community-based energy sharing network.

- Eligible member is a registered prosumer, who is capable of meeting the 'Eligible Energy Threshold' defined by the community coordinator.

- Evaluation Period is defined by the community coordinator for each new member when a new member joins the community group. This evaluates the prosumers based on the energy contribution they can make within a predefined consecutive number of energy transactions within the evaluation period. The evaluation period is said to be 'successful' if the prosumer shows the status of 'eligible member' in all energy transactions during the evaluation period.

- Flexible community membership is assigned to the new prosumers after each energy transaction within the evaluation period based on their energy contribution. The prosumers are assigned to different membership categories, but offered the same rate of incentives within this period. The main purpose of this is to evaluate the stability of a prosumer, that is, his capacity to remain at the same community-group membership level and/or maintain the eligibility status.

- Base Rate means the incentives offered to the new members in flexible groups during the evaluation period; this value is analogous to the incentives offered for Bronze level incentives.

- Stable Member is a registered prosumer who retains the 'Eligible Member' status during all the energy transactions within the 'Evaluation Period'.

- Unstable Member is a registered prosumer, who fails to keep the 'Eligible Member' status during one or more energy transactions within the 'Evaluation Period'.

- Fixed community-group membership is given to a 'Stable member' after the evaluation period. The membership level of a stable prosumer depends on the minimum energy contribution made during the successful evaluation period.

- Active member is a stable member who acquires a fixed community group membership after the evaluation period. Fig. 4 illustrates the position of registered prosumers, eligible members and the active members within the prosumer base. Accordingly, the active members are a subset of eligible members, registered members and the entire prosumer-base.

Active Members = Stable members $\subseteq$ Eligible members $\subseteq$ Registered prosumers $\subseteq$ Prosumer base 


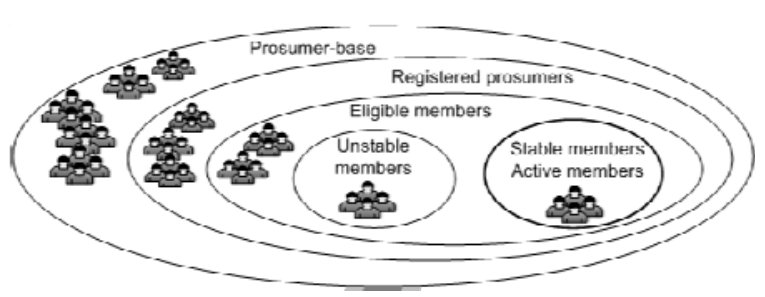

Figure 4. Position of different member status

Now we discuss the methodology we will utilize to complete stage 2. This stage starts with the evaluation period definition process, whereby the community coordinator defines the fundamental parameters of the 'Evaluation period', namely the 'Eligible energy threshold' $\left(E_{t h}\right)$ and the number of consecutive energy transactions (n) successfully fulfilled by the prosumer within the 'Evaluation period'. The measurement of the prosumer's realtime energy behaviour is made by the smart meters, which is the input to this stage. Then this energy measurement is forwarded to the initial filtering stage, where this figure is compared with the $E_{t h}$. If the new prosumer achieves $E_{t h}$, this 'Eligible prosumer' is allocated to the nearest community group membership based on the distance measure with the energy contribution he made and is assigned a 'Flexible community membership' level. On the other hand, if the new prosumer fails to achieve $E_{t h}$, that prosumer is said to have failed the evaluation. Only if the registered prosumer becomes an 'Eligible member' after $1^{\text {st }}$ energy transaction, will that prosumer be transferred to the $2^{\text {nd }}$ energy transaction. Likewise, the same process will be repeated for $n$ number of transactions for the prosumer who becomes an 'Eligible member' in the last $(n-1)$ transactions. The complete approach concludes with a final assessment phase, in which the community coordinator performs an overall appraisal of the registered prosumer within the evaluation period. The community coordinator acknowledges the registered prosumer as a 'Stable member', who maintained the 'Eligible member' status for continuous $n$ number of energy transactions within the evaluation period, or as an 'Unstable member' who fails to become an 'Eligible member' during at least one energy transaction within the evaluation period. If the prosumer is a 'Stable member', that prosumer will be assigned a 'Fixed community membership level' and 'Active member' status. The 'Membership category' is decided according to the least amount of energy the prosumer shared within the evaluation period. The fundamental benefit of introducing the Evaluation period is that the community coordinator can evaluate the sustenance of registered prosumers before assigning them to fixed membership levels. The fact of assigning the prosumers to the fixed community membership level based on the minimum amount of energy supplied by the prosumer during the energy transactions during the evaluation period minimizes the uncertainty attached to the varying energy sharing behaviours.

\section{Conclusions and Future Work}

In this paper, we extensively analyze the existing literature on the involvement and management of prosumers in SG energy-sharing process and highlight the open research issues. It is evident that most of the previous contributions in the field of SG energy sharing have overlooked the issue of managing prosumers. In order to encourage more sustainable prosumer participation and an effective management scheme, we suggest a novel concept of goal-oriented virtual prosumer communities. We identify the challenging tasks that should be undertaken to establish, consolidate and manage a prosumer community, by familiarizing ourselves with the various aspects and characteristics of existing social network communities. Finally, we demonstrate an innovative framework for forming prosumer communities. In future research, we will extend our framework to develop systematic methodologies to promote prosumer community growth and improve overall prosumers community management, and we will endeavor to resolve the shortcomings identified in the existing literature.

\section{References}

[1] US department of energy, (2011) 'International Energy Outlook 2011'; http://www.eia.doe.gov/oiaf/ieo/world.html, 2011, (05/04/2011).

[2] 'Customer Led Network Evolution'; http://www.networkrevolution.co.uk/whyarewedoingthis/abo uttheproject/whatisasmartgrid, (02/04/2011).

[3] X. Fang. S. Misra, and G. Xue, "Smart Grid - The New and Improved Power Grid: A Survey", accepted in IEEE Communications Surveys and Tutorials (COMST), in press.

[4] A.J. D. Rathnayaka, V. M. Potdar, and S.Kuruppu, "An Innovative Approach to Manage Prosumers in Smart Grid", in World Congress of Sustainable Technologies, UK, 2011, pp141-146.

[5] A.J. D. Rathnayaka, V. M. Potdar, and S.Kuruppu, "Identifying Prosumer's Energy Sharing Behaviours for Optimal Prosumer-Communities ", International Conference on Cloud and Service Computing (CSC2011), Hongkong, 2011.

[6] S. Rahman, "Smart grid expectations [In My View]", Power and Energy Magazine, IEEE, vol. 7, pp. 88, 84-85, 2009.

[7] R. Belhomme, R. C. R. D. Asua, G. Valtorta, A. Paice, F. Bouffard, R. Rooth, et al., "ADDRESS - active demand for the smart grids of the future", IET Seminar Digests, vol. 2008, no. 12380, pp. 33, 2008.

[8] A. Schröder, T. Dreyer, And B. Brelie, "Intelligent SelfDescribing Power Grids", in CIRED Seminar 2008: SmartGrids for Distribution, Frankfurt, June, 2008. 
[9] Independent Electricity System Operator, "Demand Response Project",

http://www.ieso.ca/imoweb/consult/demandresponse.asp, $(30 / 03 / 2011)$

[10] "iDEaS: Intelligent Decentralised Energy-Aware Systems", http://www.ideasproject.info/index.php. (05/04/2011)

[11] Mihai, "Virtual Power Plants: A solutionfor diminishing the barriers for the penetration of uncontrollable resources", http://www.susplan.eu/fileadmin/susplan/documents/present ations/WS_Bucharest/SUSPLAN_07_Sanduleac_VirtualPower-Plants.pdf. (30/03/2011).

[12] D. Pudjianto, C. Ramsay, and G. Strbac, "Virtual power plant and system integration of distributed energy resources", IET Renewable Power Generation, vol. 1, no. 1, pp. 10-16, 2007.

[13] "Project Summary: eTelligence", 2008, http://etelligence.de/etelligence.php, (30/03/2011).

[14] A. L. Dimeas, and N. D. Hatziargyriou, "Agent based control of Virtual Power Plants", in International Conference on Intelligent Systems Applications to Power Systems, 2007. ISAP 2007, 2007, pp. 1-6.

[15] G. Chalkiadakis, V. Robu, R. Kota, A. Rogers and N. Jennings, "Cooperatives of Distributed Energy Resources for Efficient Virtual Power Plants", in The Tenth International Conference on Autonomous Agents and Multiagent Systems (AAMAS-2011), Taipei, Taiwan, 2011.

[16] "Virtual community," http://glossary.assistnz.com/glossarylist/virtualcommunity, (1/4/2011).

[17] I. Radovanović, J. Lukkien, S. Chen, C. Molanus and T. Özçelebi, "Virtual community management for enabling p $2 p$ services in the ims network", in International Conference on Internet Multimedia Services Architecture and Applications, 2008.

[18] L. Backstrom, D. Huttenlocher, J. Kleinberg and X. Lan, "Group formation in large social networks: membership, growth, and evolution," in Proceedings of the 12th ACM SIGKDD International Conference on Knowledge Discovery and Data Mining, Philadelphia, PA, USA, 2006, pp. 44-54.

[19] S.-C. Baek, S. Kang, H. Noh and S.-W. Kim, "ContentsBased Analysis of Community Formation and Evolution in Blogspace", in Proceedings of the 2009 IEEE International Conference on Data Engineering, 2009, pp. 1607-1610.

[20] J. Porra, and M. Parks, "Sustainable virtual communities: suggestions from the colonial model", Information Systems and E-Business Management, vol. 4, no. 4, pp. 309-341, 2006. 